\title{
Leiomyoma and Nutrition, a Case-Control Study
}

\author{
Soheila Bani ${ }^{1}$, Shirin Hasanpour ${ }^{1 *}$, Solmaz Jalali chaychi ${ }^{1}$, Hossein Ebrahimi ${ }^{1}$, Mehrangiz \\ Ebrahimi Mamaghani ${ }^{2}$
}

\section{Article History: \\ Received March 2013 \\ Accepted April 2013 \\ Available online May 2013}

\section{Keywords:}

Uterine leiomyoma

Nutrition

Life style

\section{Corresponding Author:}

Shirin Hasanpour, Instructor of Nursing \& Midwifery Faculty, Tabriz University of Medical Sciences, Iran. Tel: +989141151057

Email: shirinhasanpoor@yahoo.com

\begin{abstract}
Objectives: Uterine leiomyoma is one of the most common benign tumors of the uterus that causes so many problems for women such as uterine bleeding. Medical treatment of this disease is temporary so women may be compelied to hysterectomy that is definitive treatment of leiomyoma. Nowadays researches show that most of the diseases can be prevented by changing the life style.

Researches emphasize the role of healthy nutrition in preventing the diseases, so the aim of this study is the comparison of nutrition in women with and without uterine leiomyoma in Tabriz 2012.

Material and Methods: In this case-control study with convenience sampling, we selected 400 persons with eligibility criterion of research, 200 leiomyomato persons in case group and 200 persons without leiomyoma in control group that were matched in age and parity. After obtaining informed consent, the questionnaires which contain demographic and nutritional information were given to participants to complete.

The data were analyzed by SPSS software (Ver. 13).

Results: Results showed that the mean scores of the two groups in terms of nutrition were not statistically significant, but compared to the control group the mean scores of case group were higher $(\mathrm{p}>0.05)$.

Conclusion: The results of this study indicated that the intake of beneficial nutrients was higher in control group and this may be associated with risk of leiomyoma, so encouraging people to modify their diet seems essential.
\end{abstract}

1-Nursing \&Midwifery Faculty, Tabriz University of Medical Sciences, Iran.

2-Health and Nutrition Faculty, Tabriz University of Medical Sciences, Iran. 


\section{Introduction:}

Uterine leiomyoma is one of the most common benign pelvic tumors occurs in women. This tumor consists of smooth muscles and different amounts of fibro connective tissues (1). Leiomyoma appears clinically in $25 \%$ of women throughout their life. In a study done in 1990, the samples of hysterectomy were evaluated ; according to results, the incidence of leiomyoma was $33 \%$ based on clinical findings, $50 \%$ based on ultrasonic and $77 \%$ based on histological findings (2).

One of the most common signs reported in women with leiomyoma is profuse menstrual bleeding. The pattern of bleeding is similar to menorrhagia, hypermenorrhea and polymenorrhea which would cause iron deficiency and mental problems. Another sign of leiomyoma is pelvic pressure that occurs as a result of the increased uterus size or the pressure of some kinds of myoma on adjacent organs such as colon and bladder that would consequently cause constipation and polyuria $(3,4,5)$.

Nowadays it has been proved that personal health not only depends on genetics; environmental factors; cultural and economical conditions; accessibility of information, and health care, but also depends on personal habits and life styles as well (6). W.H.O (World Health Organization) explains life style as a clear and definable patterns of behavior that could be accessible based on interaction between individual's characteristics, social relations, environmental conditions and social positions $(7,8)$.

Nowadays it is believed that $70 \%$ of illnesses are related to individual's life style. W.H.O reported in 2002 that certain changes in dietary habits, reducing physical activity, and tobacco using has been effective in occurence of chronic diseases in developing countries $(9,10)$.
The possible risk factors of leiomyoma are: black race, high BMI (body mass index), menarche in younger ages, age more than 40, being nulliparous, hormone therapy after menopause, Tamoxifen and alcohol use. There are some factors that reduce leiomyoma such as: being multiparous, the postmenopausal period, smoking and DMPA (Depot medroxyprogesterone acetate) use $(11,12)$. Paradoxical results were seen in some studies investigating the effect of nutrition on leiomyoma. In a study done in 2008, there was no relationship between consumption of carotenoid-containing foods and leiomyoma (14). In a similar study in America in 2008, there was found no relationship between the diet in general, high-fiber diet, soya and leiomyoma but in this study, drinking alcohols increased leiomyoma (15). In another study in 2007, there was a direct relationship between tomato powder and reduced uterine tube myoma in Japanese quail (16). Besides, in a research done in 1997, meat consumption increased the risk of leiomyoma incidence, but vegetable consumption decreased it (17).

As there is high prevalence of leiomyoma with side effects (e.g. hysterectomy), changing life style is one of the ways to improve health (13). Therefore, this study was done with the aim of comparing the role of nutrition in women with and without uterine leiomyoma. Identifying the risk factors helps the health care professionals to organize their activities and improve health and life style of patients; as health workers especially midwives are in close relationship with patients, their help could eliminate these problems by consultation and modifying life style in these patients. The results of this research could be useful for health organizations authorities in order to help the patients to improve their knowledge and modify their life style. 


\section{Material \& Methods:}

This research is a case-control study with convenience sampling which was conducted in Alzahra hospital of Tabriz. The aim of this study is to compare the nutrition in women with and without uterine leiomyoma. Case group was selected among women who referred to ultrasonic section of Alzahra and Taleghani hospitals with ultrasonic diagnosis of myoma.

Women who referred to this section for another reason except uterine leiomyoma and matched to case group in age and parity were selected as control group.

The sample size was 400 persons that half of them were in case group and the other half in control group. The data collected by questionnaire. At first, the researcher formulated a tool based on the objectives of the research and then in order to investigate the content validity, the questionnaire was given to 10 academic members of Tabriz University of Medical Sciences. After proving the validity, the reliability of the questionnaire was confirmed by Cronbach's alpha test $(\mathrm{R}=0.82)$.

The questionnaire consisted of sociodemographic information and the questions was related to nutrients and the list of commonly consumed foods such as: meat, meat products ( sausages, kielbasa, chicken, fish, egg), and viscera ( liver), nuts ( walnut), fruits, vegetables, garlic, onion and tomato. The nutrients were investigated and compared in women with and without leiomyoma were divided into 2 groups: meat and its products, fruits and vegetables. The data were analyzed with descriptive (frequency distribution, mean, standard deviation) and inferential statistics (independent sample T-test) by SPSS software (version 13).

\section{Results:}

Mean of the maternal age was about 27/28 \pm Half of the participants of each group were in the age range of 41-50. The illiteracy in women with leiomyoma was more than women without it. There was no significant difference between two groups in their marital status and habitation place while the women with leiomyoma were in low-income families (Table 1). There was no significant difference between obstetric history of two groups in gravida, parity, contraceptive method and BMI (body mass index), (Table 2).

Tables 3 and 4 respectively show the frequency of meat, fruits and vegetables using in two groups. The mean score of using meat products, fruits and vegetables in healthy persons was significantly more than women with myoma $(\mathrm{p}<0.05)$. There was no significant difference between two groups in other nutrients.

\section{Discussion:}

The number of studies which investigated the effects of nutrients in myoma cases is very limited. In a study done by Nagata et al (2006 there was no relationship between fat, soy or high-fiber diet and uterine myoma but alcohol increased the risk of myoma that is in harmoney with our results (15). Shahin et al (2007) in a case-control study in Turkey examined using Lycopene compounds and tomato powder in preventing of myoma in Japanese quail; results showed that using more antioxidant compounds such as tomato prevents uterine myoma that was not in agreement with our study. The reason of this contradiction may be the use of human samples instead of quail in our study (16).

In a review study on etiology and pathogenesis of uterine myoma done by Gordon Flick et al. (2003), consumption of meat, pork and other meat products increased uterine myoma while using antioxidants such as fruits and vegetables decreased it; this was not consistant with our study. The reason may be due to the different life style and consumption of different nutrient in other countries in comparison with our country (17). In a study on the relationship between using Lycopene, Carotene and uterine myoma, done by Catherin Trey et al. (2008), it was found that in smokers who used Carotene, 
the probability of diagnosing uterine myoma is more than other people.

that is not in agreement with our study (14).

Conclusion: As the results of this study couldn't emphasize enough on the role of nutrients in preventing myoma, but in comparing women with and without uterine myoma, the mean score of nutrition in healthy persons is more than the mean score of women with myoma. This may be related to high income of healthy people and may be showed better nutrition in healthy individulals. So according to the study, we can encourage women to modify their diet.

The limitations of this study were Failure to control some of confounding factors, the crowded ultrasonic sections, Lack of detailed answers to all questions by women and impossibility of generalizing results to all women.

According to the results of this study, it is suggested to do a research on the effect of Variety of nutrients in order to prevent the risk of uterine myoma.

\section{Conflict of interest statement:}

We declare that we have no conflict of interest.

\section{Acknowledgments:}

We would like to appreciate the authorities of Tabriz Faculty of Nursing and Midwifery, Alzahra Hospital and all the women who helped us in this study. 
Table 1: The comparison of demographic criteria in case and control group .

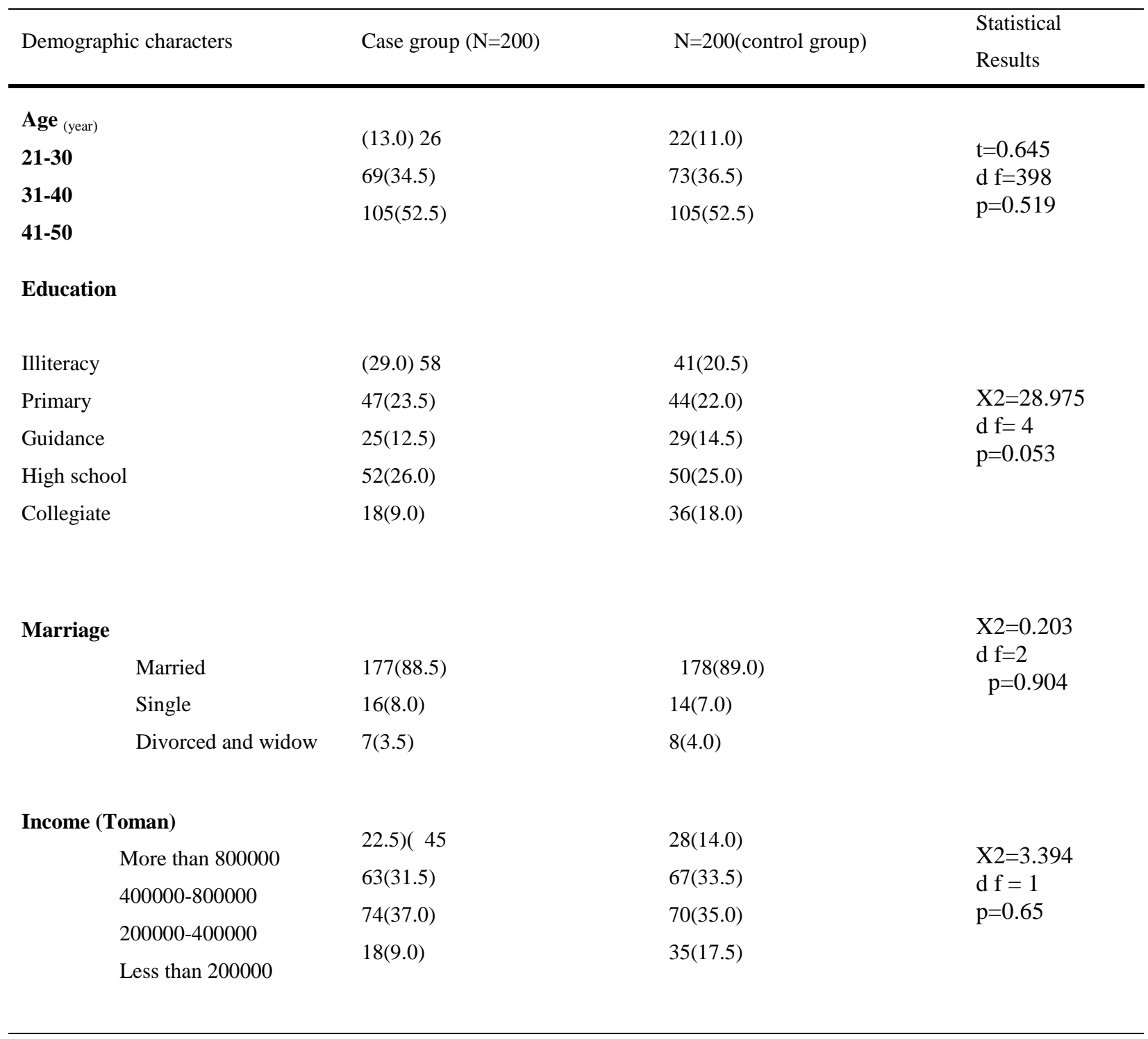


Table 2: The comparison of Obstetric history, BMI and Contraception method in case and control group

\begin{tabular}{|c|c|c|c|}
\hline Characters & Case group ( $N=200$ ) & $\mathrm{N}=200$ (control group) & $\begin{array}{c}\text { Statistical } \\
\text { Results }\end{array}$ \\
\hline Gravid & 36 & 34 & \multirow{6}{*}{$\begin{array}{c}\mathrm{t}=0.725 \\
\mathrm{df}=398 \\
\mathrm{P}=0.525\end{array}$} \\
\hline inavia & 22 & 4 & \\
\hline 1 & 39 & 27 & \\
\hline 2 & 28 & 43 & \\
\hline 3 & \multirow{2}{*}{75} & 32 & \\
\hline$>=4$ & & 64 & \\
\hline Pariety & & & \multirow{6}{*}{$\begin{array}{c}\mathrm{t}=1.873 \\
\mathrm{df}=398 \\
\mathrm{P}=0.945\end{array}$} \\
\hline 1 & 43 & 37 & \\
\hline 2 & 34 & 36 & \\
\hline 3 & 41 & 54 & \\
\hline$>=4$ & 30 & 24 & \\
\hline BMI & 52 & 49 & \\
\hline \multicolumn{4}{|l|}{$<18.5$} \\
\hline $18.5-25$ & 1 & 3 & \multirow{5}{*}{$\begin{array}{c}\mathrm{t}=0.651 \\
\mathrm{df}=398 \\
\mathrm{P}=0.515\end{array}$} \\
\hline $25-30$ & 46 & 44 & \\
\hline \multirow[t]{2}{*}{$>30$} & 93 & 81 & \\
\hline & 60 & 72 & \\
\hline \multicolumn{3}{|l|}{$\begin{array}{l}\text { Contraception } \\
\text { method }\end{array}$} & \\
\hline OCP & 22 & 16 & \multirow{8}{*}{$\begin{array}{c}\mathrm{X} 2=7.267 \\
\mathrm{~d} f=7 \\
\mathrm{p}=0.402\end{array}$} \\
\hline Candom & 26 & 30 & \\
\hline DMPA & 5 & 4 & \\
\hline IUD & 17 & 25 & \\
\hline Interrupted & 25 & 34 & \\
\hline $\mathrm{TL}$ & 40 & 26 & \\
\hline Vasectomy & 10 & 11 & \\
\hline No method & 55 & 54 & \\
\hline
\end{tabular}


Table 3: The comparison of meat and its productions use in case and control group

\begin{tabular}{lccc}
\hline \multicolumn{1}{c}{ Meat Products } & $\begin{array}{c}\text { Case group }(\mathrm{N}=200) \\
\text { mean } \pm_{\mathrm{sd}}\end{array}$ & $\begin{array}{c}\text { control group(N=200) } \\
\text { mean } \pm_{\mathrm{Sd}}\end{array}$ & $\mathrm{P}$ \\
\hline Nuts (walnut ,...) & $2.1 \pm 1.7$ & $1.8 \pm 1.6$ & 0.53 \\
\hline Meat & $3.5 \pm 3$ & $9.4 \pm 46.4$ & 0.172 \\
\hline Meat products (sausages,..) & $0.3 \pm_{0.2}$ & $0.4 \pm_{0.5}$ & 0.001 \\
\hline Chicken & $2.0 \pm 1.8$ & $1.94 \pm_{1.99}$ & 0.423 \\
\hline Fish & $0.5 \pm_{0.8}$ & $0.7 \pm 1$ & 0.51 \\
\hline Egg & $2.7 \pm 3.2$ & $3.3 \pm 2.9$ & 0.64 \\
\hline Viscera & $0.3 \pm 0.6$ & $0.3 \pm 0.7$ & 0.799 \\
\hline Bean & $2.1 \pm 1.7$ & $1.8 \pm 1.6$ & 0.441 \\
\hline
\end{tabular}

Table 4: The comparison of fruits and vegetables use in case and control group

\begin{tabular}{lccc}
\hline \multicolumn{1}{c}{ Fruits and Vegetables } & $\begin{array}{c}\text { Case group }(\mathrm{N}=200) \\
\text { mean } \pm \mathrm{sd}\end{array}$ & $\begin{array}{c}\text { control group(N=200) } \\
\text { mean } \pm \mathrm{sd}\end{array}$ & $\mathrm{P}$ \\
\hline Season fruits & $5.5 \pm 6.5$ & $6.8 \pm 7.8$ & 0.725 \\
\hline Juicy fruits & $3.7 \pm 3$ & $4.0 \pm 2.9$ & 0.530 \\
\hline Leafy vegetables & $3.8 \pm 3.4$ & $3.9 \pm 3.2$ & 0.506 \\
\hline Herbs & $5.6 \pm 2.7$ & $3.2 \pm 2.4$ & 0.134 \\
\hline Garlic and Paz & $3.3 \pm 3.4$ & $3.5 \pm 3.9$ & 0.055 \\
\hline Vegetable such as carrot and peas & $2.5 \pm 2.1$ & $1.9 \pm 1.6$ & 0.147 \\
\hline Tomato & $4.1 \pm 5.1$ & $5.2 \pm 5.8$ & 0.041 \\
\hline
\end{tabular}




\section{References:}

1.Gharekhani p, Sadatian A. Women Diseases CMMD, Nour danesh publication 2003; 436: 44-49 (Persian).

2. Okolo S. Incidence, Etiology and Epidemiology of uterine fibroids. ELSEVIER 2008; 22(4): 572.

3.Anderia Donayf B,Kistner Gynecology \&Women's Health ,Translate by Dr Bahram Ghazi jahani,5ed,Golban Publication 1999, p155(Persian).

4.Gupta S ,Jose J, Mnyonda I.Clinical presentation of fibroids .ELSEVIER 2008; 22(4): 615.

5. Stott P.C. The outcome of menorrhagia: A retrospective case control study. Journal of the Royal College of General Practitioners 1983; 33(256): 715

6. Anderson RN, Posener N. Relationship between experiencing menopause .In Journal of nursing practice, 2002; 8: 265-73.

7.Tirodimos I, Georgouvia I,Savva T-N,Karanika E,Noukari D. Healthy lifestyle habits among Greek university students: differences by sex and faculty of Study. Eastern Mediterranean Health Journal 2009; 15(3): 722.

8. Hamdi zeidy, E;Heidarnia e;Hajizadeh, a:"Study of lifestyle in Heart Diseases patients" Journal of shahed university 2006,50-54.(Persian).

9.Hossein nejad A,Soltani A,Adibi A,Hamidy Z."Relationship between lifestyle and bone mass density".Tabib sharg journal 2005; 2: 15-20 (Persian).

10.Hodani F, Sargolzai M, Ghorbani A,"Relationship between lifestyle with depression or anexity in sabzevar university students". Journal of sabzevar medicine university.2000; 7: 2023(Persian).

11. Wise L, Palmer J, Harlow B, Spiegelman D, Stewart E, Adams-Campbell L, Rosenberg L. Reproductive Factors, Hormonal Contraception, and Risk of Uterine Leiomyomata in African-American Women: A Prospective Study. American journal of epidemiology 2004; 159(2): 113.

12. Flake G, Andersen J, Darlene D. Etiology pathogenesis of uterine leiomyomas: a review. Environmental health perspectives 2003; 111(8): 1037-1041.

13. Mitchell MK. Nutrition across the life span (No. Ed. 2).Philadelphia: W.B sanders 2003, 357. 
14. Terry K, Missmer S, Hankionson S, Willett W,Vivo I. Lycopene and other cartenoid intake in relation to risk of uterine leiomyomata. American journal of obstetrics 2008; 198(37): 37.

15.Nagata ch, Nakamura K, Oba sh ,Hayashi M, Takede N, Yasuda K. Association of intakes of fat,dietary fibre,soya isoflavones and alcohol with uterine fibroids in Japanese women. British journal of nutrition 2008; 101: 1430

16. Sahin K, Ozercan R, Onderci M, Sahin N, Khachik F, Seren S, Kucuk O. Dietary tomato powder supplementation in the prevention of leiomyoma of the oviduct in the Japanese quail. Nutr Cancer 2007; 59(1):1.

17. Flake G, Andersen J, Darlene D. Etiology pathogenesis of uterine leiomyomas: a review. Environmental health perspectives, 2003; 111(8): 1037-1041. 